\title{
Assessment of PET Tracer Uptake in Hormone-Independent and Hormone-Dependent Xenograft Prostate Cancer Mouse Models
}

\author{
Damaris Kukuk ${ }^{1}$, Gerald Reischl ${ }^{1}$, Olivier Raguin ${ }^{2}$, Stefan Wiehr ${ }^{1}$, Martin S. Judenhofer ${ }^{1}$, Carsten Calaminus ${ }^{1}$, \\ Valerie S. Honndorf ${ }^{1}$, Leticia Quintanilla-Martinez ${ }^{3}$, Tanja Schönberger ${ }^{4}$, Olivier Duchamp ${ }^{2}$, Hans-Jürgen Machulla ${ }^{1}$, \\ and Bernd J. Pichler ${ }^{1}$ \\ ${ }^{I}$ Department of Preclinical Imaging and Radiopharmacy, Laboratory for Preclinical Imaging and Imaging Technology of the Werner \\ Siemens-Foundation, Eberhard Karls University, Tübingen, Germany; ${ }^{2}$ Oncodesign Biotechnologies, Dijon Cedex, France; ${ }^{3}$ Institute \\ for Pathology, Eberhard-Karls University, Tübingen, Germany; and ${ }^{4}$ Department of Internal Medicine III, University Hospital, \\ Tübingen, Germany
}

The pharmacokinetics of ${ }^{18} \mathrm{~F}$-fluorodeoxythymidine (FLT), ${ }^{18} \mathrm{~F}$ FDG, ${ }^{11} \mathrm{C}$-choline, and ${ }^{18} \mathrm{~F}$-fluoroethylcholine (FEC) in 2 hormoneindependent (PC-3, DU145) and 2 hormone-dependent (CWR22, PAC120) prostate cancer xenograft mouse models were evaluated by PET and compared by immunohistochemistry. Further investigation was performed to determine whether PET can detect early changes in tumor metabolism after androgen ablation therapy through surgical castration. Methods: PET was performed on 4 consecutive days. In addition, the CWR22 and PAC120 tumor models were surgically castrated after the baseline measurement and imaged again after castration. The tracer uptake was analyzed using time-activity curves, percentage injected dose per volume $\left(\% \mathrm{ID} / \mathrm{cm}^{3}\right)$, and tumor-to-muscle ratio (T/M). Results: Regarding the hormone-independent prostate tumor models, ${ }^{18} \mathrm{~F}$-FLT showed the best T/M and highest \%ID/cm ${ }^{3}$ in PC-3 $\left(2.97 \pm 0.63 \% \mathrm{ID} / \mathrm{cm}^{3}\right)$ and DU145 $\left(2.06 \pm 0.75 \% \mathrm{ID} / \mathrm{cm}^{3}\right)$ tumors. ${ }^{18} \mathrm{~F}-\mathrm{FDG}$ seemed to be the tracer of choice for delineation of the PC-3 tumors but not for the DU145 tumors. Using ${ }^{11} \mathrm{C}$-choline (PC-3: $1.33 \pm 0.29$ $\%$ ID/cm ${ }^{3}$, DU145: $1.60 \pm 0.27 \%$ ID/cm ${ }^{3}$ ) and ${ }^{18} \mathrm{~F}-\mathrm{FEC}$, we did not find any significant uptake in the tumors, compared with muscle tissue. Regarding the hormone-dependent prostate tumor models, the CWR22 model showed a highly significant $(P<0.01)$ decrease in tumor ${ }^{18} \mathrm{~F}-\mathrm{FDG}$ uptake from $4.11 \pm 1.29 \%$ $\mathrm{ID} / \mathrm{cm}^{3}$ to $2.19 \pm 1.45 \% \mathrm{ID} / \mathrm{cm}^{3}$ after androgen ablation therapy. However, the ${ }^{18} \mathrm{~F}-\mathrm{FLT},{ }^{11} \mathrm{C}$-choline, or ${ }^{18} \mathrm{~F}-\mathrm{FEC}$ tracers did not provide sufficient uptake or reliable information about therapy response in CWR22 tumors. The PAC120 model showed a significant increase in ${ }^{18} \mathrm{~F}-\mathrm{FLT}$ tumor uptake $(P=0.015)$ after androgen ablation therapy. The accumulation of ${ }^{18} \mathrm{~F}-\mathrm{FEC}$ (before: $2.32 \pm$ $1.01 \% \mathrm{ID} / \mathrm{cm}^{3}$, after: $\left.1.36 \pm 0.39 \% \mathrm{ID} / \mathrm{cm}^{3}\right)$ was found to be the next highest after ${ }^{18} \mathrm{~F}-\mathrm{FDG}$ (before: $2.45 \pm 0.93 \% \mathrm{ID} / \mathrm{cm}^{3}$, after: $\left.2.18 \pm 0.65 \% \mathrm{ID} / \mathrm{cm}^{3}\right)$ in PAC120 tumors before castration and is better suited for monitoring therapy response. Conclusion: This comprehensive study in 2 hormone-dependent and 2 hormone-independent prostate tumor mouse models

Received Dec. 19, 2010; revision accepted Jun. 30, 2011.

For correspondence or reprints contact: Bernd J. Pichler, Department of Preclinical Imaging and Radiopharmacy, Röntgenweg 13, 72076 Tuebingen, Germany.

E-mail: bernd.pichler@med.uni-tuebingen.de

Published online Aug. 22, 2011.

COPYRIGHT $\odot 2011$ by the Society of Nuclear Medicine, Inc. shows that ${ }^{18} \mathrm{~F}-\mathrm{FLT}$ and ${ }^{18} \mathrm{~F}-\mathrm{FDG}$ are the most appropriate tracers for delineation of PC-3, DU145 (except ${ }^{18} \mathrm{~F}-\mathrm{FDG}$ ), and CWR22 tumors, but not for PAC120 tumors. ${ }^{18} \mathrm{~F}-\mathrm{FEC}$ and ${ }^{11} \mathrm{C}-$ choline, in particular, revealed insufficient $\mathrm{T} / \mathrm{M}$ ratio in the prostate tumor models. The results may indicate that radiolabeled choline and choline derivatives compete with a high concentration of the precursor dimethylaminoethanol, resulting in reduced uptake in small-rodent tumor models, a hypothesis that is currently under investigation in our laboratory.

Key Words: prostate cancer mouse models; PET; ${ }^{11} \mathrm{C}$-choline; ${ }^{18} \mathrm{~F}-\mathrm{FEC}$; immunohistochemistry

J Nucl Med 2011; 52:1654-1663

DOI: 10.2967/jnumed.110.086702

$\mathbf{P}$ rostate cancer is the most prominent oncologic disease in men in the western world. Its spectrum ranges from insignificant, indolent cancer to aggressive stages with metastasis formation. This heterogeneity of prostate carcinoma makes it a difficult disease to diagnose and treat.

Although serum prostate-specific antigen is the most important diagnostic indicator of prostate malignancy used clinically, it fails to accurately track disease progression (1) and does not provide any information about regional or distant metastasis (2). Furthermore, it fails to differentiate between malignant carcinoma and benign prostatic hyperplasia or inflammation. Therefore, establishing a method that allows for the primary diagnosis and staging of prostate cancer and enables the following of treatment success or disease progression over long periods is of prime importance.

In the field of oncology, molecular imaging, PET specifically, provides important information for primary diagnosis, accurate staging, and detection of metastasis. After the development of combined PET/CT, prostate imaging using radiolabeled tracers was improved, enabling an exact segmentation of unspecific tracer accumulation in the bladder and specific tissue uptake (3). Considering the current 
activities in developing combined PET/MRI, prostate cancer diagnosis using PET tracers may become even more used for routine clinical diagnosis in the future $(4,5)$.

Currently, the clinical gold standard in PET oncology is ${ }^{18} \mathrm{~F}-\mathrm{FDG}$. However, ${ }^{18} \mathrm{~F}$-FDG is not suitable for imaging prostate carcinoma $(6,7)$. The high bladder activity of ${ }^{18} \mathrm{~F}-$ FDG creates difficulty in differentiating between malignant prostate tissue and benign prostatic hyperplasia or inflammation. ${ }^{18} \mathrm{~F}-\mathrm{FDG}$ is transported most effectively through glucose transporters 1 and 3 (GLUT-1 and GLUT-3, respectively) in cancer cells (8). However, glucose metabolism in well-differentiated prostate carcinoma cells is often lower than in cells of other tumor types, leading to low tumor ${ }^{18} \mathrm{~F}-\mathrm{FDG}$ uptake and insufficient image contrast (9). This decreased metabolism could be because most prostate carcinoma cells are less metabolically active and slower growing than cells of other tumor types.

Another PET tracer for cancer imaging is ${ }^{18} \mathrm{~F}$ fluorodeoxythymidine (FLT), a marker for cell proliferation (10). ${ }^{18} \mathrm{~F}-\mathrm{FLT}$ may also be of potential interest for imaging prostate carcinoma because the intracellular target of ${ }^{18} \mathrm{~F}-\mathrm{FLT}$ is thymidine kinase 1 (TK-1) (11). Clinical studies have shown that ${ }^{18} \mathrm{~F}-\mathrm{FLT}$ may be a promising tracer for predicting and monitoring response to therapy in breast cancer $(12,13)$. So far, ${ }^{18} \mathrm{~F}$-FLT has been used for imaging prostate cancer only in preclinical studies (14).

The PET tracers currently most used for clinical prostate imaging are ${ }^{11} \mathrm{C}$-choline and its derivates. ${ }^{11} \mathrm{C}$-choline is transported into the tumor cell, phosphorylated by choline kinase $\alpha$, and incorporated as phosphatidylcholine into the cell membrane (15). A major advantage of ${ }^{11} \mathrm{C}$-choline is its low bladder activity, especially in comparison to ${ }^{18} \mathrm{~F}-$ labeled tracers such as FDG. Thus, ${ }^{11} \mathrm{C}$-choline is already used for imaging prostate carcinoma in clinical diagnosis, generally as a staging biomarker during neoadjuvant and adjuvant therapies and for clarification of a relapse after treatment. However, ${ }^{11} \mathrm{C}$-choline is rarely used for primary diagnosis (16). Unfortunately, the exact biochemical background of choline metabolism still remains unclear and clinical PET studies validating ${ }^{11} \mathrm{C}$-choline are often contradictory (17-19). After surgery, use of ${ }^{11} \mathrm{C}$-choline often raises questions concerning differentiating relapsed malignant tissue from surgical necrosis or inflammation. Additionally, ${ }^{11} \mathrm{C}$-choline does not always confirm a prostate-specific antigen increase or decrease $(20,21)$. Another drawback of ${ }^{11} \mathrm{C}$-choline is the short half-life $(20 \mathrm{~min})$ of the isotope ${ }^{11} \mathrm{C}$, which requires on-site production and is therefore not suitable for distribution among clinical satellite centers. Thus, two ${ }^{18} \mathrm{~F}$-labeled derivates of ${ }^{11} \mathrm{C}$-choline, ${ }^{18} \mathrm{~F}$-fluoroethylcholine (FEC) and ${ }^{18} \mathrm{~F}$-fluorocholine (FCh), have been developed. These tracers supposedly have in vivo biodistribution and pharmacokinetics similar to ${ }^{11} \mathrm{C}$-choline $(22,23)$. Although ${ }^{18} \mathrm{~F}-\mathrm{FEC}$ and ${ }^{18} \mathrm{~F}-\mathrm{FCh}$ show similar clinical results to choline and have the advantage of a 2-h halflife, their renal clearance and subsequent high degree of bladder activity rely on PET/CT.
Another PET tracer candidate for imaging prostate cancer is ${ }^{11} \mathrm{C}$-acetate (24), which was, however, not evaluated in this study. This tracer is displayed with low bladder activity and pharmacokinetics similar to ${ }^{11} \mathrm{C}$-choline (25).

The aim of this work was to validate ${ }^{11} \mathrm{C}$-choline and ${ }^{18} \mathrm{~F}$-FEC in 4 different mouse models of human prostate cancer and compare them with the gold standards ${ }^{18} \mathrm{~F}-$ FLT and ${ }^{18} \mathrm{~F}-\mathrm{FDG}$. The different pharmacokinetics of the tracers and their uptake characteristics were evaluated by small-animal PET in mouse xenograft models of 2 human hormone-independent cancer cell lines, PC-3 and DU145, and 2 hormone-dependent tumor models, CWR22 and PAC120. Subsequently, we evaluated the effect of castration on the uptake characteristics of the 4 different tracers through the CWR22 and PAC120 mouse models. The in vivo imaging results were cross-correlated with immunohistochemistry.

\section{MATERIALS AND METHODS}

A detailed description of the preparation of the radiopharmaceuticals ${ }^{18} \mathrm{~F}$-FDG, ${ }^{18} \mathrm{~F}$-FLT, ${ }^{11} \mathrm{C}$-choline, and ${ }^{18} \mathrm{~F}$-FEC, as well as of the animal models, tumor inoculation, and grafting, can be found in the supplemental data (supplemental materials are available online only at http://jnm.snmjournals.org). Furthermore, hematoxylin and eosin staining and immunohistochemistry are specified in the supplemental notes.

\section{PET}

PET for the hormone-independent PC-3 and DU145 model was performed using the microPET Focus scanner (Siemens) (26). All PET data were corrected for decay and dead time; however, our standard mouse imaging protocols do not include attenuation correction.

Dynamic and static small-animal PET was performed when the tumors had reached a mean size $\left( \pm\right.$ SD) of $278 \pm 239 \mathrm{~mm}^{3}$ for PC-3 $(n=12)$ or $58 \pm 21 \mathrm{~mm}^{3}$ for DU145 $(n=11)$ (first imaging day) (Supplemental Fig. 1). Tumor volumes were assessed by external measurement with a caliper along the long axis (length a) and the short axis (width b). Volume was calculated by the following formula: $(\operatorname{radical}(\mathrm{a} \times \mathrm{b})) \times(\mathrm{a} \times \mathrm{b}) \times 0.5236$ (approximated to the volume calculation of an ellipsoid).

The mice were imaged on 4 consecutive days with the 4 different tracers: ${ }^{18} \mathrm{~F}$-FLT, ${ }^{18} \mathrm{~F}-\mathrm{FDG},{ }^{11} \mathrm{C}$-choline, and ${ }^{18} \mathrm{~F}-\mathrm{FEC}$. The tracers were injected through the lateral tail vein. Dynamic animal PET data were acquired in list mode over $1.5 \mathrm{~h}$ for ${ }^{18} \mathrm{~F}$ FDG, over $2 \mathrm{~h}$ for ${ }^{18} \mathrm{~F}$-FLT and ${ }^{18} \mathrm{~F}$-FEC, and over $1 \mathrm{~h}$ for ${ }^{11} \mathrm{C}$ choline. Time-activity curves were used to determine the optimal uptake time in the tumor for each tracer and each tumor mouse model. On the basis of this information, 20-min static scans were obtained at $50 \mathrm{~min}$ (PC-3) and $10 \mathrm{~min}$ (DU145) after injection of ${ }^{18} \mathrm{~F}-\mathrm{FDG}$, at $50 \mathrm{~min}$ (PC-3 and DU145) after injection of ${ }^{18} \mathrm{~F}-\mathrm{FLT}$, and at $60 \mathrm{~min}(\mathrm{PC}-3)$ or $30 \mathrm{~min}$ (DU145) after injection of ${ }^{18} \mathrm{~F}$ FEC.

All ${ }^{11} \mathrm{C}$-choline scanning was performed as dynamic scans over $1 \mathrm{~h}$. For all ${ }^{18} \mathrm{~F}$ tracers, a total activity of $10 \pm 2 \mathrm{MBq}$ per mouse was injected, whereas for ${ }^{11} \mathrm{C}$-choline, $13 \pm 3 \mathrm{MBq}$ was injected. During ${ }^{18} \mathrm{~F}$-FLT and ${ }^{18} \mathrm{~F}$-FEC tracer uptake, the mice were awake, whereas the animals were warmed and kept under anesthesia during ${ }^{18} \mathrm{~F}$-FDG tracer uptake. 
PET for the hormone-dependent CWR22 and PAC120 models was performed using an Inveon small-animal PET scanner (Siemens) $(27,28)$.

Dynamic and static small-animal PET was performed when tumors had reached a mean size of $481 \pm 333 \mathrm{~mm}^{3}$ for CWR22 ( $n=18,4-6 \mathrm{wk}$ after implantation [first imaging day]) or $73 \pm 49$ $\mathrm{mm}^{3}$ for PAC120 $(n=19,6-8 \mathrm{wk}$ after implantation [first imaging day]) (Supplemental Fig. 2). The animals were imaged using the same imaging protocols and same animal-handling procedures as described for the PC-3 and DU145 tumor-bearing mice.

Again, on the basis of the dynamic data, static scans were performed at $60 \mathrm{~min}$ after injection of ${ }^{18} \mathrm{~F}-\mathrm{FDG}$, at $60 \mathrm{~min}$ (CWR22) or 50 min (PAC120) after injection of ${ }^{18}$ F-FLT, and at $60 \mathrm{~min}$ after injection of ${ }^{18} \mathrm{~F}$-FEC. The first 4 consecutive days of imaging served as the baseline measurement for the hormonedependent mouse models. After this baseline, the CWR22 and PAC120 tumor-bearing mice were surgically castrated and again imaged 2-3 wk after castration.

After the last scan, the animals were sacrificed and tumors were excised for further evaluation by immunohistochemistry and histology. During dynamic and static measurements, the mice were warmed through a heating pad and kept under anesthesia by $1.5 \%$ isoflurane evaporated in $0.8 \mathrm{~L}$ of $\mathrm{O}_{2}$ per minute. For ${ }^{18} \mathrm{~F}-$ FDG measurements, the animals were kept fasting for $9-15 \mathrm{~h}$ before tracer injection.

PET image reconstruction was performed with 2-dimensional iterative ordered-subset expectation maximization. The reconstructed PET images were analyzed with the software package AsiPro (Siemens). After decay correction and normalization of the data to the injected activity, 3-dimensional regions of interest based on the visually identified size of the tumor were drawn. Three regions of interest were placed over 3 consecutive slices in the shoulder muscle, serving as control regions.

Tracer uptake was analyzed by retrieving time-activity curves from the dynamic scans, percentage injected dose per volume $\left(\% \mathrm{ID} / \mathrm{cm}^{3}\right)$, and tumor-to-muscle ratio $(\mathrm{T} / \mathrm{M})$. The presented data are pooled data from 2 or 3 studies per xenograft model. We conducted our investigations at least twice per tumor model to verify our findings. All imaging studies were performed in our laboratory.

\section{Statistics}

Differences in tracer uptake were compared using the 2-tailed Student $t$ test, type 3. Data were represented as the mean \pm SD. A value of $P$ less than 0.05 was considered as statistically significant, and a value of $P$ less than 0.01 as highly statistically significant.

\section{RESULTS}

\section{PET of PC-3 and DU145 Tumor Models}

The best in vivo tumor delineation from muscle tissue was observed with ${ }^{18}$ F-FLT (Fig. 1) for both mouse models. The time-activity curves of the tumors (Fig. 1A) reached a plateau at about 3,600 s after tracer injection. At the same time, the time-activity curve of the muscle uptake showed a significant tracer washout. Therefore, the PET scans started at $50 \mathrm{~min}$ after injection, which covered the plateau of tracer uptake and revealed $2.97 \pm 0.63 \% \mathrm{ID} / \mathrm{cm}^{3}$ for PC3 and $2.06 \pm 0.75 \% \mathrm{ID} / \mathrm{cm}^{3}$ for DU145 (Fig. 1B). The ${ }^{18} \mathrm{~F}-$ FLT muscle $\% \mathrm{ID} / \mathrm{cm}^{3}$ in the static scans (PC-3: $0.90 \pm$ 0.14, DU145: $0.74 \pm 0.28$ ) showed almost the same values for both animal models.
Static ${ }^{18} \mathrm{~F}-\mathrm{FDG}$ PET data revealed an uptake in PC-3 tumors of $2.32 \pm 0.62 \% \mathrm{ID} / \mathrm{cm}^{3}$, and the DU145 tumors showed $2.10 \pm 0.30 \% \mathrm{ID} / \mathrm{cm}^{3}$ (scan started $600 \mathrm{~s}$ after injection) at the time point with the highest tracer accumulation (Fig. 1). The ${ }^{18} \mathrm{~F}-\mathrm{FDG}$ muscle uptake was lower for $\mathrm{PC}-3\left(1.22 \pm 0.30 \% \mathrm{ID} / \mathrm{cm}^{3}\right)$ than for DU145 $(1.57 \pm 0.36$ $\left.\% \mathrm{ID} / \mathrm{cm}^{3}\right)$. The equilibrium for the PC-3 tumors was reached at approximately 2,700 s after tracer injection. The dynamic curves (Fig. 1A) reveal that ${ }^{18} \mathrm{~F}-\mathrm{FDG}$ is not trapped in DU145 tumor cells.

The pharmacokinetics of ${ }^{11} \mathrm{C}$-choline demonstrated a rapid initial tracer uptake into both tumors, which reached a constant plateau in the time-activity curve at 180-300 s after injection (Fig. 1A). At 1,200 s after injection, however, both tumor cell lines showed only a low uptake: $1.33 \pm 0.29$ $\% \mathrm{ID} / \mathrm{cm}^{3}$ for PC-3 and $1.60 \pm 0.27 \% \mathrm{ID} / \mathrm{cm}^{3}$ for DU145 (Fig. 1B). The uptake of ${ }^{11} \mathrm{C}$-choline in the muscle was between $1.35 \pm 0.42 \% \mathrm{ID} / \mathrm{cm}^{3}$ (PC-3) and $1.34 \pm 0.37$ $\% \mathrm{ID} / \mathrm{cm}^{3}$ (DU145).

${ }^{18}$ F-FEC pharmacokinetics and uptake in the PC-3 and DU145 tumors were comparable to ${ }^{11} \mathrm{C}$-choline. ${ }^{18} \mathrm{~F}$-FEC reached $1.73 \pm 0.17 \% \mathrm{ID} / \mathrm{cm}^{3}$ at $3,600 \mathrm{~s}$ after injection in the PC-3 tumors and $1.54 \pm 0.36 \% \mathrm{ID} / \mathrm{cm}^{3}$ at $1,800 \mathrm{~s}$ after injection in the DU145 tumors (Fig. 1B). The ${ }^{18} \mathrm{~F}-\mathrm{FEC}$ uptake in the muscle was $1.27 \pm 0.28 \% \mathrm{ID} / \mathrm{cm}^{3}$ for the PC-3 mice and $1.12 \pm 0.21 \% \mathrm{ID} / \mathrm{cm}^{3}$ for the DU145 mice.

The best T/Ms for the PC-3 (3.31 \pm 0.54$)$ and DU145 $(2.80 \pm 0.61)$ tumors were achieved with ${ }^{18} \mathrm{~F}$-FLT. ${ }^{18} \mathrm{~F}-$ FDG revealed a significant difference between the T/Ms of PC-3 (1.96 \pm 0.54$)$ and DU145 (1.38 \pm 0.33$)$. The $\mathrm{T} / \mathrm{Ms}$ of PC-3 tumors were $1.05 \pm 0.32$ for ${ }^{11} \mathrm{C}$-choline and $1.41 \pm 0.29$ for ${ }^{18} \mathrm{~F}$-FEC. Only a moderate ${ }^{11} \mathrm{C}$-choline uptake could be found in DU145 tumors, leading to a T/M of $1.26 \pm 0.35$, similar to ${ }^{18} \mathrm{~F}$-FEC with a $\mathrm{T} / \mathrm{M}$ of $1.38 \pm$ 0.21. Supplemental Figure 3 shows representative PET images.

\section{Immunohistochemistry of PC-3 and DU145 Tumors}

The histologic and immunohistochemical analysis performed with antibodies against Ki67, TK-1, GLUT-1, and GLUT-3 for the 2 hormone-independent tumor entities are shown in Supplemental Figure 4. Hematoxylin and eosin staining of the PC-3 tumor showed a diffuse solid growth of large neoplastic cells with moderate nuclear pleomorphism and abundant mitoses (Supplemental Fig. 4A). Ki67 staining confirmed the high proliferation index of the tumor cells, with a mean value of $75 \%$. In contrast, TK-1 staining revealed a mean proliferation index of $51 \%$. GLUT-1 was expressed in a relatively high percentage of the tumor cells; in contrast, GLUT-3 was not expressed (Supplemental Fig. 4A). The histologic analysis of the DU145 cells reveals tumors characterized by a diffuse growth pattern composed of pleomorphic cells with numerous mitoses (Supplemental Fig. 4B). The Ki67 staining showed a mean proliferation index of $65 \%$, with a TK-1 index of $40 \%$. GLUT-1 staining was observed only in isolated cells (arrow), whereas GLUT-3 


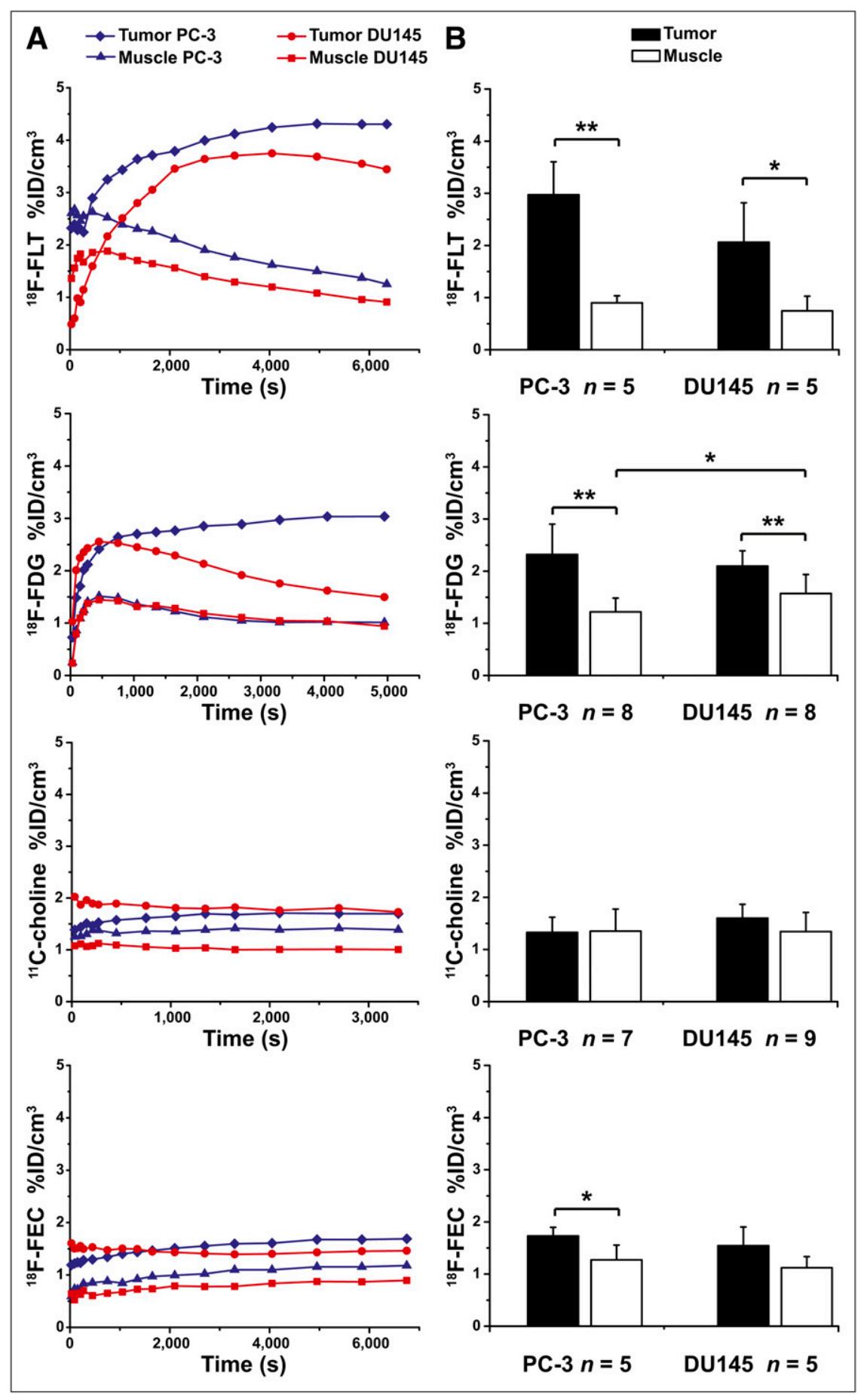

\section{B}

FIGURE 1. (A) Representative time-activity curves in $\% \mathrm{ID} / \mathrm{cm}^{3}$ from particular tracer imaged in subcutaneous hormone-independent prostate tumor mouse models PC-3 and DU145. (B) Static mean tumor and muscle uptake in $\% \mathrm{ID} / \mathrm{cm}^{3}$. Error bars represent SD. ${ }^{\star} P<0.05$. ${ }^{\star} P<0.01$. was found in small groups of cells (arrows) (Supplemental Fig. 4B).

\section{PET of CWR22 and PAC120 Tumors}

After the baseline measurements with all 4 tracers, the animals were surgically castrated and imaged again at 2 (PAC120) or 3 (CWR22) weeks after castration to investigate possible changes in tumor tracer uptake caused by simulated androgen ablation therapy. Castration led to a volume reduction in CWR22 tumors (baseline: $481 \pm 333 \mathrm{~mm}^{3}$
( $n=18$ ) [first imaging day]; 3 wk after castration: $280 \pm$ $180 \mathrm{~mm}^{3}$ ( $n=11$ ) [first imaging day]). A change of tracer uptake on PET after therapy was observed earlier than a reduction in tumor volume in PAC120 tumors (baseline: $73 \pm 49 \mathrm{~mm}^{3}$ ( $\left.n=19\right)$ [first imaging day]; $2 \mathrm{wk}$ after castration: $100 \pm 60 \mathrm{~mm}^{3}(n=11)$ [first imaging day]) (29) (Supplemental Fig. 2B), and a clear change of tumor microenvironment was seen in the immunohistochemistry 2 wk after castration. 
CWR22. The time-activity curves of ${ }^{18} \mathrm{~F}-\mathrm{FLT}$ showed nearly no tracer trapping in the CWR22 tumors (Fig. 2A), resulting in $1.38 \pm 0.65 \% \mathrm{ID} / \mathrm{cm}^{3} 3,600 \mathrm{~s}$ after injection; for the muscle, the value was $0.69 \pm 0.24 \% \mathrm{ID} / \mathrm{cm}^{3}$ (Fig. 2B). There was a slight decrease of tracer accumulation in the tumor, to $1.16 \pm 0.65 \% \mathrm{ID} / \mathrm{cm}^{3}$, at $3 \mathrm{wk}$ after castration (Fig. 2B). For the muscle uptake, we saw a significant increase of tracer accumulation, from $0.69 \pm 0.24 \% \mathrm{ID} /$ $\mathrm{cm}^{3}$ to $1.19 \pm 0.51 \% \mathrm{ID} / \mathrm{cm}^{3}(P=0.024)$, after castration (Fig. 2B).

In the CWR22 tumor model, the time-activity curve (Fig. 2A) showed a slow accumulation of ${ }^{18} \mathrm{~F}-\mathrm{FDG}$ in the tumor and the formation of a plateau at 3,600 s after injection $\left(4.11 \pm 1.29 \% \mathrm{ID} / \mathrm{cm}^{3}\right.$, Fig. $\left.2 \mathrm{~B}\right)$. The ${ }^{18} \mathrm{~F}-\mathrm{FDG}$ muscle uptake was $1.44 \pm 0.55 \% \mathrm{ID} / \mathrm{cm}^{3}$. After therapy, the CWR22 model showed a significant $(P=0.008)$ decrease
FIGURE 2. (A) Representative time-activity curves in $\% \mathrm{ID} / \mathrm{cm}^{3}$ of particular tracer in subcutaneous tumors of hormone-dependent prostate cancer tumor mouse model CWR22 before and after castration. (B) Static mean data of tracer uptake in tumors and muscle for CWR22 mouse model in $\% \mathrm{ID} / \mathrm{cm}^{3}$. Error bars represent SD. p.c. $=$ after castration. ${ }^{\star} P<0.05$. ${ }^{\star \star} P<0.01$.

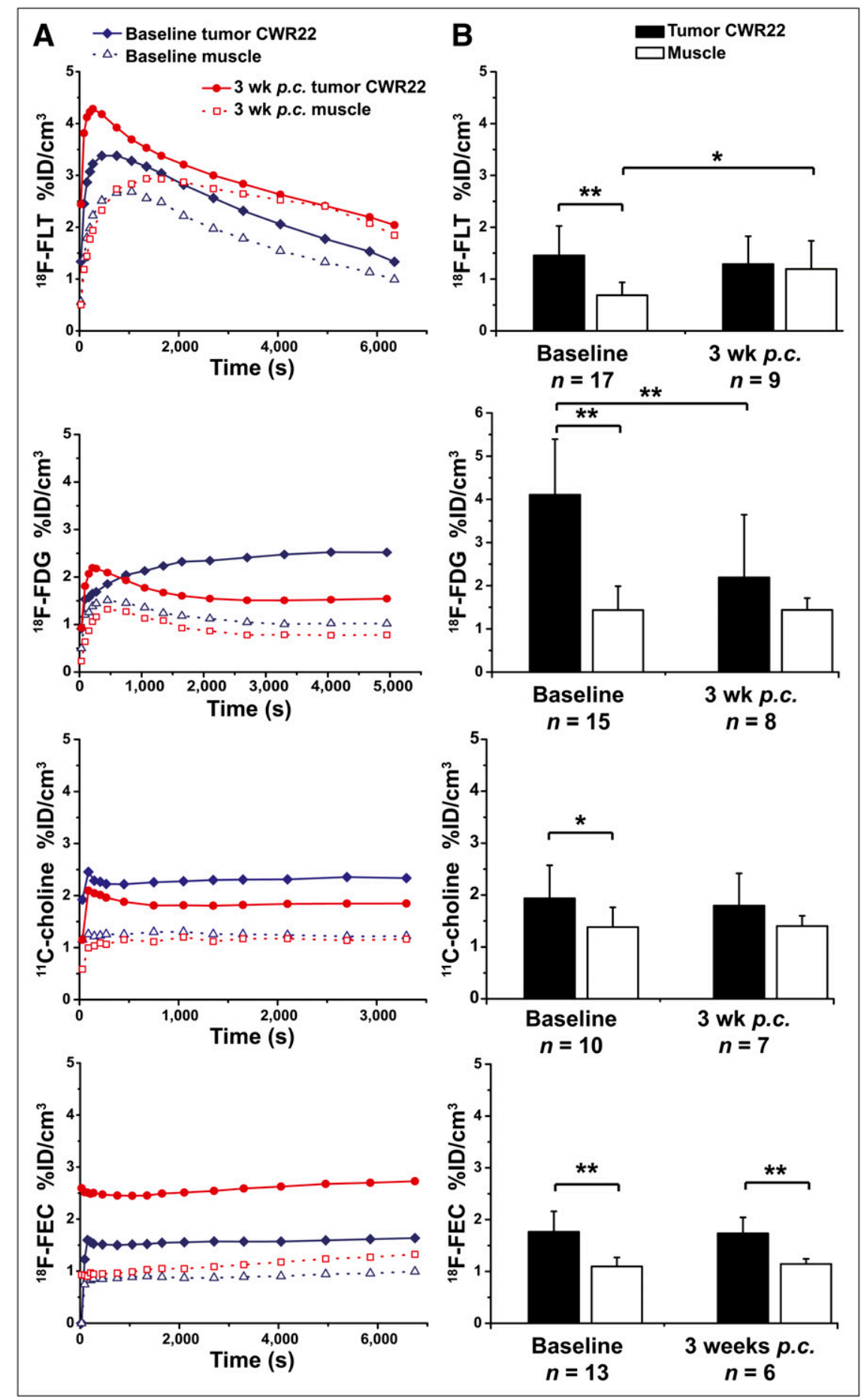


of ${ }^{18} \mathrm{~F}-\mathrm{FDG}$ in the tumor $\left(2.19 \pm 1.45 \% \mathrm{ID} / \mathrm{cm}^{3}\right.$, Fig. $\left.2 \mathrm{~B}\right)$, whereas muscle uptake remained stable after castration.

With ${ }^{11} \mathrm{C}$-choline and ${ }^{18} \mathrm{~F}$-FEC, the CWR22 tumors had a pattern similar to the PC-3 and DU145 tumors. The pharmacokinetics of ${ }^{11} \mathrm{C}$-choline and ${ }^{18} \mathrm{~F}$-FEC demonstrated a rapid initial tracer uptake, reaching a constant plateau at 180-300 s after injection (Fig. 2A). For the baseline measurements, the CWR22 tumors presented a moderate uptake of ${ }^{11} \mathrm{C}$-choline at $1,200 \mathrm{~s}$ after injection $(1.94 \pm 0.64 \% \mathrm{ID} /$ $\mathrm{cm}^{3}$ ) and a moderate uptake of ${ }^{18} \mathrm{~F}-\mathrm{FEC}$ at $3,600 \mathrm{~s}$ after injection $\left(1.77 \pm 0.39 \% \mathrm{ID} / \mathrm{cm}^{3}\right)$. After therapy, a small decrease in tumor uptake was detected with ${ }^{11} \mathrm{C}$-choline $\left(1.79 \pm 0.62 \% \mathrm{ID} / \mathrm{cm}^{3}\right)$, whereas no changes were seen with ${ }^{18}$ F-FEC $\left(1.73 \pm 0.31 \% \mathrm{ID} / \mathrm{cm}^{3}\right.$, Fig. 2B). Tracer accumulation into the muscle did not change significantly for ${ }^{11} \mathrm{C}$-choline or ${ }^{18} \mathrm{~F}$-FEC after surgical castration.

A highly significant decrease, caused by the increased muscle uptake after castration, for the T/M was found with ${ }^{18}$ F-FLT (before: $2.04 \pm 0.65$, after: $0.99 \pm 0.42$ ). However, this decrease did not relate to any change in the tumor accumulation. Using ${ }^{18} \mathrm{~F}-\mathrm{FDG}$, we observed a highly significant $(P=0.0064)$ decrease in the T/M $(3.14 \pm 1.15$ to $1.62 \pm$ 1.08) until 3 wk after castration. Neither ${ }^{11} \mathrm{C}$-choline nor ${ }^{18} \mathrm{~F}$ FEC showed significant differences in the T/M of the CWR22 model. Both tracers showed only a slight decrease in the T/M $\left({ }^{11} \mathrm{C}\right.$-choline before: $1.50 \pm 0.56$, after: $1.29 \pm$ 0.46 ; ${ }^{18}$ F-FEC before: $1.62 \pm 0.32$, after: $1.52 \pm 0.25$ ). Supplemental Figure 5 displays representative PET images from the CWR22 tumor model before and after therapy.

PAC120. The PAC120 tumor model demonstrated a rapid but low accumulation followed by washout of ${ }^{18} \mathrm{~F}$-FLT in the dynamic PET images (Fig. 3A). Subsequently, PAC120 tumors showed a $\% \mathrm{ID} / \mathrm{cm}^{3}$ of only $1.13 \pm 0.75$ and $0.86 \pm$ 0.44 in the muscle at $3,000 \mathrm{~s}$ after injection (Fig. 3B). We observed a significant increase $(P=0.015)$ in the ${ }^{18} \mathrm{~F}$-FLT tumor uptake $\left(1.99 \pm 0.75 \% \mathrm{ID} / \mathrm{cm}^{3}\right)$ at $2 \mathrm{wk}$ after castration (Fig. 3B). Additionally, similar to the CWR22 model, muscle uptake increased after castration $(1.39 \pm 0.49 \% \mathrm{ID} /$ $\mathrm{cm}^{3}$ ).

Using ${ }^{18} \mathrm{~F}-\mathrm{FDG}$, we observed a rapid uptake into the tumor followed by a constant plateau after 2,000 s after injection (Fig. 3A). The $\% \mathrm{ID} / \mathrm{cm}^{3}$ of the tumors was $2.45 \pm 0.93$ at $3,600 \mathrm{~s}$ after injection, and the $\% \mathrm{ID} / \mathrm{cm}^{3}$ of the muscle was $2.17 \pm 1.12$ at the baseline measurement (Fig. 3B). Mimicking androgen ablation therapy by castration decreased ${ }^{18} \mathrm{~F}$-FDG tracer muscle uptake significantly $\left(1.23 \pm 0.32 \% \mathrm{ID} / \mathrm{cm}^{3}, P=0.0091\right)$, compared with a moderately decreased tumor uptake $(2.18 \pm 0.65 \% \mathrm{ID} /$ $\left.\mathrm{cm}^{3}\right)$.

With ${ }^{11} \mathrm{C}$-choline and ${ }^{18} \mathrm{~F}$-FEC we saw a similar pattern for all investigated prostate tumor models; the pharmacokinetics of ${ }^{11} \mathrm{C}$-choline and ${ }^{18} \mathrm{~F}$-FEC demonstrated a rapid initial tracer uptake into the PAC120 tumors that reached a plateau at $180-300 \mathrm{~s}$ after injection (Fig. 3A). ${ }^{11} \mathrm{C}$-choline reached $1.17 \pm 0.74 \% \mathrm{ID} / \mathrm{cm}^{3}$ before and $1.55 \pm 0.56$ $\% \mathrm{ID} / \mathrm{cm}^{3}$ after castration at $1,200 \mathrm{~s}$ after injection (Fig.
3B). Muscle uptake changed from $1.12 \pm 0.13 \% \mathrm{ID} / \mathrm{cm}^{3}$ to $1.06 \pm 0.02 \% \mathrm{ID} / \mathrm{cm}^{3}$. Neither alteration was statistically significant.

${ }^{18} \mathrm{~F}-\mathrm{FEC}$ showed the second-highest (after ${ }^{18} \mathrm{~F}-\mathrm{FDG}$ ) uptake in this tumor model $\left(2.32 \pm 1.01 \% \mathrm{ID} / \mathrm{cm}^{3}\right.$ before and $1.36 \pm 0.39 \% \mathrm{ID} / \mathrm{cm}^{3}$ after castration, $P=0.022$ ) (Fig. 3B). No significant changes in tracer uptake were found in the muscle (before: $1.28 \pm 0.31 \% \mathrm{ID} / \mathrm{cm}^{3}$, after: $1.10 \pm$ $\left.0.07 \% \mathrm{ID} / \mathrm{cm}^{3}, P=0.073\right)$. The ${ }^{18} \mathrm{~F}-\mathrm{FEC}$ pharmacokinetics were similar and comparable to ${ }^{11} \mathrm{C}$-choline.

${ }^{18} \mathrm{~F}-\mathrm{FLT}$ showed no change in T/M (before: $1.39 \pm 0.26$, after: $1.44 \pm 0.25$ ). The ${ }^{18} \mathrm{~F}-\mathrm{FDG} \mathrm{T} / \mathrm{M}$ of PAC120 demonstrated an increase from $1.29 \pm 0.44 \% \mathrm{ID} / \mathrm{cm}^{3}$ at baseline to $1.83 \pm 0.50 \% \mathrm{ID} / \mathrm{cm}^{3}$ at 2 wk after castration $(P=$ 0.019). The T/M of ${ }^{11} \mathrm{C}$-choline showed an increase from $1.01 \pm 0.52$ to $1.47 \pm 0.51$ after castration. For ${ }^{18} \mathrm{~F}$-FEC, we noticed a decrease in the $\mathrm{T} / \mathrm{M}$ from $1.85 \pm 0.88$ to $1.25 \pm 0.35$ after castration. Supplemental Figure 6 displays representative PET images from the PAC120 tumor model before and after therapy.

\section{Immunohistochemistry of CWR22 and PAC120 Tumors}

CWR22. The results of the histologic and immunohistochemical analyses of CWR22 tumors are displayed in Supplemental Fig. 7. The hematoxylin and eosin staining showed a diffuse growth pattern with areas of necrosis (arrows) and abundant mitosis. The Ki67 staining confirmed a high proliferation index with a mean of $60 \%$ before treatment. At $3 \mathrm{wk}$ after castration, the hematoxylin and eosin staining revealed a dramatic reduction of tumor cells and an increase in macrophages and fat cells (clear areas). Mitoses were rather rare. The Ki67 staining showed a low mean proliferation index of $3 \%$, demonstrating the efficacy of androgen ablation therapy. The TK-1 staining showed results similar to the Ki67 staining (before: 32\% positive, after: $1 \%$ positive) (Supplemental Fig. 7). GLUT-1 was expressed in a minority of tumor cells (arrow) before castration; at 3 wk after castration, no expression of GLUT-1 was observed. GLUT-3 was not expressed in CWR22 tumors.

PAC120. Supplemental Figure 8 displays the results of the histologic and immunohistochemical analyses of PAC120 tumors. The hematoxylin and eosin staining showed tumors with a solid, diffuse growth pattern and abundant mitoses. In contrast to the CWR22 tumors, almost no necrosis was observed. The Ki67 staining showed a high mean proliferation index of $63 \%$ before treatment. At 2 wk after castration, hematoxylin and eosin staining revealed regression of the tumors, with reduced tumor cell content and abundant macrophages and fat cells. The mitosis index was reduced to $20 \%$. The TK-1 index was relatively low and changed from $24 \%$ to $13 \%$. GLUT-1 showed results similar to the CWR22 tumors, with only moderate expression before treatment and no expression after treatment. Similarly, GLUT-3 expression was not observed. 


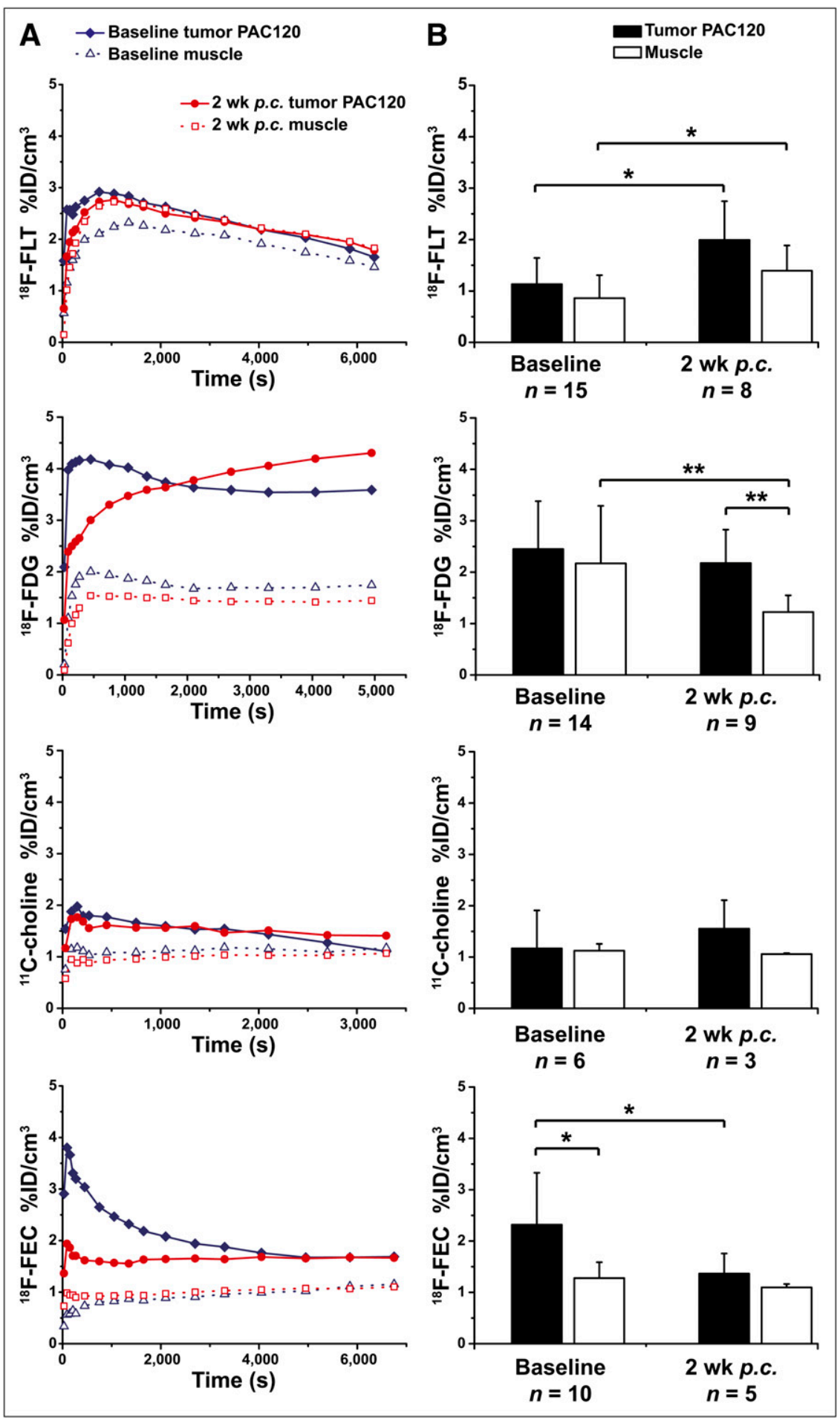

FIGURE 3. (A) Representative time-activity curves in $\% \mathrm{ID} / \mathrm{cm}^{3}$ of particular tracer in PAC120 tumor mouse model before and after castration. (B) Static mean data of tumor and muscle in $\% 1 D / \mathrm{cm}^{3}$ for PAC120 mouse model. Error bars represent SD. p.c. $=$ after castration. ${ }^{\star} P<0.05$. ${ }^{\star \star} P<0.01$.

\section{DISCUSSION}

In this project, we investigated the uptake characteristics of ${ }^{18} \mathrm{~F}$-FLT, ${ }^{18} \mathrm{~F}$-FDG, ${ }^{11} \mathrm{C}$-choline, and ${ }^{18} \mathrm{~F}$-FEC in 2 human hormone-independent prostate tumor models, PC-3 and DU145, and 2 hormone-dependent models, CWR22 and PAC120. The tracer pharmacokinetics were evaluated before and after surgical castration in the CWR22 and PAC120 mouse models, mimicking androgen ablation therapy.
${ }^{18} \mathrm{~F}-\mathrm{FLT}$ showed the highest $\% \mathrm{ID} / \mathrm{cm}^{3}$ and best T/M for PC-3 and DU145 (Fig. 1). ${ }^{18}$ F-FDG also displayed sufficient, although lower, absolute uptake and poorer T/M than ${ }^{18} \mathrm{~F}$-FLT. The dynamic data showed identical ${ }^{18} \mathrm{~F}$-FLT uptake characteristics for PC-3 and DU145 tumors. Although ${ }^{18} \mathrm{~F}-\mathrm{FDG}$ showed a slow but high uptake in PC-3 tumors, there was lower uptake in DU145 tumors and a significant washout starting at $500 \mathrm{~s}$ after injection. 
By contrast, we did not find sufficient uptake of ${ }^{11} \mathrm{C}$ choline and ${ }^{18} \mathrm{~F}-\mathrm{FEC}$ in these tumor entities. For both tumors, the dynamic measurements of ${ }^{11} \mathrm{C}$-choline and ${ }^{18} \mathrm{~F}$-FEC showed a fast but low tracer uptake and a plateau over $3,600 \mathrm{~s}$ or $7,200 \mathrm{~s}$, respectively.

The ${ }^{18}$ F-FLT uptake observations were consistent with the Ki67 and TK-1 immunohistochemistry (Supplemental Fig. 4A). Although Ki67 does not necessarily correlate with ${ }^{18} \mathrm{~F}$-FLT uptake (30), in this case it does better reflect the ${ }^{18} \mathrm{~F}-\mathrm{FLT}$ uptake than TK-1. GLUT-1 was elevated in PC-3 tumors but only moderately in DU145 (Supplemental Fig. 4B). This result could explain the low ${ }^{18}$ F-FDG uptake and the washout characteristics of the DU145 tumors. Therefore, the ${ }^{18} \mathrm{~F}-\mathrm{FDG}$ uptake within the first $1,000 \mathrm{~s}$ most probably results from the blood-pool activity. The static ${ }^{18}$ F-FDG PET images of DU145 mice, acquired at $600 \mathrm{~s}$ after injection, revealed high activity in the liver, intestine, and muscle, leading to a low T/M but still sufficient compared with PC-3 (Supplemental Fig. 3). If we had chosen a later scanning time point, the differences in uptake measurements for PC-3 and DU145 would have been more obvious. GLUT-3 plays a minor role in DU145.

In contrast to the hormone-independent models, we observed in the CWR22 and PAC120 tumors a lower uptake of ${ }^{18}$ F-FLT. For both tumors, the time-activity curves show a strong tracer washout after the initial perfusion phase. The low uptake of the proliferation marker ${ }^{18} \mathrm{~F}$-FLT is in line with the slow growth rate of the CWR22 and PAC120 tumors (Supplemental Fig. 2). CWR22 tumors showed a sufficient and-compared with the muscle-highly significant ${ }^{18} \mathrm{~F}-$ FDG uptake. Most important, ${ }^{18} \mathrm{~F}-\mathrm{FDG}$ uptake in CWR22 tumors was significantly reduced 3 wk after castration (Fig. 2B). Compared with muscle, a low but significant ${ }^{11} \mathrm{C}$-choline uptake was found in CWR22 tumors (Fig. 2B). ${ }^{11} \mathrm{C}$-choline uptake in PAC120 tumors was at the background levels of muscle tissue (Fig. 3). However, in both tumors time-activity curves showed a fast tracer uptake that remained stable over $1 \mathrm{~h} .{ }^{18} \mathrm{~F}-\mathrm{FEC}$ also revealed low tracer uptake but highly significant T/M in the CWR22 model. Tracer uptake of ${ }^{18} \mathrm{~F}$-FEC did not change after castration. In PAC120 mice, PET scans with ${ }^{18} \mathrm{~F}$-FEC revealed a significantly higher tracer uptake in the tumor compared with the muscle before castration. After androgen ablation therapy, the ${ }^{18} \mathrm{~F}$-FEC uptake in the tumor was significantly reduced. In ${ }^{11} \mathrm{C}$-choline and ${ }^{18}$ F-FEC-PET scans, we found high levels of tracer uptake in liver, kidneys, and intestine, making delineation of the tumor in same animals difficult (Supplemental Fig. 6).

In CWR22 and PAC120, Ki67 expression was approximately $60 \%$, which was similar to that found in the PC-3 and DU145 tumors. In sharp contrast, we found a much lower TK-1 expression in hormone-dependent tumors, as might explain the low ${ }^{18}$ F-FLT uptake (Supplemental Figs. 7 and 8). Ki67 was significantly reduced after castration in CWR22 and PAC120, whereas a reduction of TK-1 was found only in CWR22. Interestingly, the reduced Ki67 and TK-1 expression was not reflected by the ${ }^{18} \mathrm{~F}-\mathrm{FLT}$ uptake of
CWR22 mice after hormone depletion (Fig. 2B). A statistically significant enhanced uptake of ${ }^{18} \mathrm{~F}$-FLT in muscle tissue was found in both mouse models after castration. GLUT-1 was elevated in CWR22 and PAC120 tumors but disappeared after surgical castration, as reflects the ${ }^{18} \mathrm{~F}$-FDG pharmacokinetics in CWR22 mice. In PAC120 tumors, ${ }^{18} \mathrm{~F}$-FDG uptake was not reduced 2 wk after castration, although GLUT-1 expression was diminished at that time (Supplemental Fig. 8). GLUT-3 seemed to play no role in either tumor model.

Particularly in the ${ }^{18}$ F-FLT-PET scans, we saw that the quantitative tracer uptake $\left(\% \mathrm{ID} / \mathrm{cm}^{3}\right)$ was significantly higher for dynamic scans than for static scans (Figs. 1-3). These findings are currently under detailed evaluation. First results indicate that the anesthesia has a strong effect on ${ }^{18} \mathrm{~F}$-FLT pharmacokinetics. A similar effect was observed for dynamic ${ }^{18}$ F-FDG scans in PC-3 tumors. However, these discrepancies between static and dynamic $\% \mathrm{ID} / \mathrm{cm}^{3}$ result from uptake values evaluated in 3 of 8 dynamic scans and were not linked to anesthesia effects because the mice were also anesthetized during the tracer uptake for static scans.

Although several clinical studies have shown the potential of ${ }^{11} \mathrm{C}$-choline, ${ }^{18} \mathrm{~F}-\mathrm{FCh}$, and ${ }^{18} \mathrm{~F}$-FEC for PET in tumors, the sensitivity and specificity for detecting prostate cancer are limited $(17,18)$. In addition, the exact relation between prostate-specific antigen and ${ }^{11} \mathrm{C}$-choline uptake is not known and the significance of clinical studies using ${ }^{11} \mathrm{C}$-choline is seen as contradictory (17-19).

Our study revealed that ${ }^{18} \mathrm{~F}$-FDG and ${ }^{18} \mathrm{~F}$-FLT are better suited than ${ }^{11} \mathrm{C}$-choline and ${ }^{18} \mathrm{~F}$-FEC for imaging hormoneindependent xenograft tumors.

${ }^{18}$ F-FLT revealed a weak but significantly higher uptake only in CWR22 tumors, compared with muscle tissue. In CWR22 tumors, ${ }^{18} \mathrm{~F}-\mathrm{FDG}$ turned out to be the best tracer for tumor detection and monitoring of therapy response. However, in the clinic ${ }^{18} \mathrm{~F}$-FDG has limitations for primary staging and imaging of metastasis in prostate cancer (31).

${ }^{11} \mathrm{C}$-choline did not provide sufficient tumor delineation and could not be used as an indication for successful androgen ablation therapy. In both hormone-dependent tumor mouse models, ${ }^{18} \mathrm{~F}$-FEC was better than ${ }^{11} \mathrm{C}$-choline, although a reduction of ${ }^{18} \mathrm{~F}-\mathrm{FEC}$ in tumors after therapy could be found only in the PAC120 xenograft tumors (Fig. 3B). Comparable results in CWR22 mice were found for ${ }^{18} \mathrm{~F}$-FLT before and after castration by Oyama et al. (14). In CWR22 and PC-3 tumors, we found a ${ }^{18} \mathrm{~F}-\mathrm{FDG}$ T/M that was approximately a factor of 2 higher than the one reported by Jadvar et al. (32). Krause et al. showed in a PC-3 tumor model a T/M of $1.8 \pm 0.4$ before treatment and was able to monitor with ${ }^{11} \mathrm{C}$-choline a therapy response when using docetaxel (33). Even a higher ${ }^{11} \mathrm{C}$-choline uptake of $12.5 \% \mathrm{ID} / \mathrm{g}$ in CWR22 and of $10.2-23.1 \% \mathrm{ID} / \mathrm{g}$ in PC-3 tumors was found by Fei et al. (34).

Our results reveal that none of the studied mouse xenograft tumor models for prostate cancer are valuable for translational examinations using ${ }^{11} \mathrm{C}$-choline or its derivates. How- 
ever, for basic research the hormone-independent PC-3 and the hormone-dependent CWR22 tumor models are good tools when ${ }^{18} \mathrm{~F}$-FLT or ${ }^{18} \mathrm{~F}$-FDG is used, as well as for therapy monitoring (CWR22) (Supplemental Table 1). Both models are easy to handle, reproducible, and reliable.

Our results further support the hypothesis from recent publications that an excess of the nonlabeled precursor dimethylaminoethanol may inhibit the specific uptake of ${ }^{11} \mathrm{C}$-choline in prostate tumors (35-39). This effect can specifically play an important role in small rodents because the ratio of injected precursor to the entire body mass is more unfavorable than in larger subjects. Unexpectedly, ${ }^{18} \mathrm{~F}$-FEC showed a higher uptake than ${ }^{11} \mathrm{C}$-choline in both hormone-dependent and PC-3 tumors, although in vitro studies showed that the uptake of fluorinated compounds such as ${ }^{18} \mathrm{~F}-\mathrm{FEC}$ in phospholipids is slower than that of ${ }^{11} \mathrm{C}$-choline $(35,40)$. The fact that we found a higher ${ }^{18} \mathrm{~F}-$ FEC than ${ }^{11} \mathrm{C}$-choline T/M may support the hypothesis of confounding uptake effects from dimethylaminoethanol because the total injected dimethylaminoethanol content was probably lower in ${ }^{18} \mathrm{~F}$-FEC studies than in ${ }^{11} \mathrm{C}$-choline studies. Rosen et al. (36) showed that the uptake of ${ }^{11} \mathrm{C}$ choline in tumors is 6 times higher when the dimethylaminoethanol concentration is under $1 \mu \mathrm{g} / \mathrm{kg}$. Leyton et al. (41) designed ${ }^{18} \mathrm{~F}$-fluoromethyl- $\left[1,2-{ }^{2} \mathrm{H}_{4}\right]$-choline, which enhances the sensitivity of tumor imaging through increased availability of substrate.

The influence of dimethylaminoethanol in prostate cancer imaging needs to be further evaluated.

\section{CONCLUSION}

Our study aimed at a comprehensive evaluation of ${ }^{18} \mathrm{~F}-$ FLT, ${ }^{18} \mathrm{~F}-\mathrm{FDG},{ }^{11} \mathrm{C}$-choline, and ${ }^{18} \mathrm{~F}$-FEC in 2 hormonedependent and 2 hormone-independent prostate tumor mouse models. We found that ${ }^{18} \mathrm{~F}-\mathrm{FLT}$ and ${ }^{18} \mathrm{~F}-\mathrm{FDG}$ reveal appropriate uptake in PC-3, DU145 (except ${ }^{18} \mathrm{~F}-\mathrm{FDG}$ ), and CWR22 but not in PAC120 prostate tumors.

${ }^{18} \mathrm{~F}$-FEC and, in particular, ${ }^{11} \mathrm{C}$-choline were not able to reveal a sufficient $\mathrm{T} / \mathrm{M}$ in most tumors. These results may confirm that radiolabeled choline and choline derivates compete with the precursor dimethylaminoethanol, resulting in reduced uptake in small-rodent prostate tumor models.

\section{DISCLOSURE STATEMENT}

The costs of publication of this article were defrayed in part by the payment of page charges. Therefore, and solely to indicate this fact, this article is hereby marked "advertisement" in accordance with 18 USC section 1734.

\section{ACKNOWLEDGMENTS}

We thank Funda Cay, Daniel Bukala, Maren Koenig, and Mareike Lehnhoff for excellent technical assistance, as well as Denis Lamparter, Anke Stahlschmidt, and Nadja Buckmüller for tracer synthesis. Further, we thank Julia Mannheim for PET imaging support. This work was supported by the
Deutsche Forschungsgemeinschaft (MA 1096/6-1, PI 771/4-2). No other potential conflict of interest relevant to this article was reported.

\section{REFERENCES}

1. Jadvar H. Molecular imaging of prostate cancer: a concise synopsis. Mol Imaging. 2009;8:56-64

2. Beardo P, Fernandez PL, Corral JM, Filella X, Alcover J. Undetectable prostate specific antigen in disseminated prostate cancer. J Urol. 2001;166:993.

3. Beheshti M, Imamovic L, Broinger G, et al. ${ }^{18} \mathrm{~F}$ choline PET/CT in the preoperative staging of prostate cancer in patients with intermediate or high risk of extracapsular disease: a prospective study of 130 patients. Radiology. 2010;254:925-933.

4. Judenhofer MS, Wehrl HF, Newport DF, et al. Simultaneous PET-MRI: a new approach for functional and morphological imaging. Nat Med. 2008;14:459-465.

5. von Schulthess GK, Schlemmer HP. A look ahead: PET/MR versus PET/CT. Eur J Nucl Med Mol Imaging. 2009;36(suppl 1):S3-S9.

6. Reske SN, Blumstein NM, Glatting G. PET and PET/CT in relapsing prostate carcinoma [in German]. Urologe A. 2006;45:1240, 1242-1244, 1246-1248, 1250.

7. Effert PJ, Bares R, Handt S, et al. Metabolic imaging of untreated prostate cancer by positron emission tomography with 18 fluorine-labeled deoxyglucose. J Urol. 1996;155:994-998.

8. Macheda ML, Rogers S, Best JD. Molecular and cellular regulation of glucose transporter (GLUT) proteins in cancer. J Cell Physiol. 2005;202:654-662.

9. Hong H, Zhang Y, Sun J, Cai W. Positron emission tomography imaging of prostate cancer. Amino Acids. 2010;39:11-27.

10. Shields AF, Grierson JR, Dohmen BM, et al. Imaging proliferation in vivo with [F-18]FLT and positron emission tomography. Nat Med. 1998;4:1334-1336.

11. Krohn KA, Mankoff DA, Eary JF. Imaging cellular proliferation as a measure of response to therapy. J Clin Pharmacol. 2001;July(suppl):96S-103S.

12. Kenny L, Coombes RC, Vigushin DM, et al. Imaging early changes in proliferation at 1 week post chemotherapy: a pilot study in breast cancer patients with $3^{\prime}$-deoxy-3'-[ $\left.{ }^{18} \mathrm{~F}\right]$ fluorothymidine positron emission tomography. Eur $\mathrm{J} \mathrm{Nucl}$ Med Mol Imaging. 2007;34:1339-1347.

13. Pio BS, Park CK, Pietras R, et al. Usefulness of 3'-[F-18]fluoro-3'-deoxythymidine with positron emission tomography in predicting breast cancer response to therapy. Mol Imaging Biol. 2006;8:36-42.

14. Oyama N, Ponde DE, Dence C, et al. Monitoring of therapy in androgen-dependent prostate tumor model by measuring tumor proliferation. J Nucl Med. 2004; 45:519-525.

15. Zheng QH, Gardner TA, Raikwar S, et al. $\left[{ }^{11} \mathrm{C}\right]$ choline as a PET biomarker for assessment of prostate cancer tumor models. Bioorg Med Chem. 2004;12:28872893.

16. Kotzerke J, Prang J, Neumaier B, et al. Experience with carbon-11 choline positron emission tomography in prostate carcinoma. Eur J Nucl Med. 2000;27:1415-1419.

17. Fazio F, Picchio M, Messa C. Is ${ }^{11} \mathrm{C}$-choline the most appropriate tracer for prostate cancer? For. Eur J Nucl Med Mol Imaging. 2004;31:753-756.

18. Zöphel K, Kotzerke J. Is ${ }^{11} \mathrm{C}$-choline the most appropriate tracer for prostate cancer? Against. Eur J Nucl Med Mol Imaging. 2004;31:756-759.

19. Greco C, Cascini GL, Tamburrini O. Is there a role for positron emission tomography imaging in the early evaluation of prostate cancer relapse? Prostate Cancer Prostatic Dis. 2008;11:121-128.

20. Rinnab L, Mottaghy FM, Blumstein NM, et al. Evaluation of $\left[{ }^{11} \mathrm{C}\right]$-choline positron-emission/computed tomography in patients with increasing prostate-specific antigen levels after primary treatment for prostate cancer. BJU Int. 2007;100:786793.

21. Reske SN. Nuclear imaging of prostate cancer: current status [in German]. Urologe A. 2007;46:1485-1499.

22. von Forstner C, Egberts JH, Ammerpohl O, et al. Gene expression patterns and tumor uptake of ${ }^{18} \mathrm{~F}-\mathrm{FDG},{ }^{18} \mathrm{~F}-\mathrm{FLT}$, and ${ }^{18} \mathrm{~F}-\mathrm{FEC}$ in PET/MRI of an orthotopic mouse xenotransplantation model of pancreatic cancer. J Nucl Med. 2008;49:13621370 .

23. DeGrado TR, Baldwin SW, Wang S, et al. Synthesis and evaluation of ${ }^{18} \mathrm{~F}-$ labeled choline analogs as oncologic PET tracers. J Nucl Med. 2001;42:18051814.

24. Oyama N, Akino H, Kanamaru H, et al. ${ }^{11} \mathrm{C}$-acetate PET imaging of prostate cancer. J Nucl Med. 2002;43:181-186.

25. Schiepers C, Hoh CK, Nuyts J, et al. $1{ }^{1}{ }^{11} \mathrm{C}$-acetate kinetics of prostate cancer. $J$ Nucl Med. 2008;49:206-215.

26. Tai YC, Ruangma A, Rowland D, et al. Performance evaluation of the microPET focus: a third-generation microPET scanner dedicated to animal imaging. $\mathrm{J} \mathrm{Nucl}$ Med. 2005;46:455-463. 
27. Constantinescu CC, Mukherjee J. Performance evaluation of an Inveon PET preclinical scanner. Phys Med Biol. 2009;54:2885-2899.

28. Kemp BJ, Hruska CB, McFarland AR, Lenox MW, Lowe VJ. NEMA NU 2-2007 performance measurements of the Siemens Inveon preclinical small animal PET system. Phys Med Biol. 2009;54:2359-2376.

29. de Pinieux G, Legrier ME, Poirson-Bichat F, et al. Clinical and experimental progression of a new model of human prostate cancer and therapeutic approach. Am J Pathol. 2001;159:753-764.

30. Dimitrakopoulou-Strauss A, Strauss LG. The role of ${ }^{18} \mathrm{~F}-\mathrm{FLT}$ in cancer imaging: does it really reflect proliferation? Eur J Nucl Med Mol Imaging. 2008;35:523-526.

31. Shreve PD, Grossman HB, Gross MD, Wahl RL. Metastatic prostate cancer: initial findings of PET with 2-deoxy-2-[F-18]fluoro-D-glucose. Radiology. 1996;199: 751-756.

32. Jadvar H, Xiankui L, Shahinian A, et al. Glucose metabolism of human prostate cancer mouse xenografts. Mol Imaging. 2005;4:91-97.

33. Krause BJ, Souvatzoglou M, Herrmann $\mathrm{K}$, et al. $\left[{ }^{11} \mathrm{C}\right]$ choline as pharmacodynamic marker for therapy response assessment in a prostate cancer xenograft model. Eur J Nucl Med Mol Imaging. 2010;37:1861-1868.

34. Fei B, Wang H, Wu C, Chiu SM. Choline PET for monitoring early tumor response to photodynamic therapy. J Nucl Med. 2010;51:130-138.
35. Mertens K, Slaets D, Lambert B, et al. PET with ${ }^{18} \mathrm{~F}$-labelled choline-based tracers for tumour imaging: a review of the literature. Eur J Nucl Med Mol Imaging. 2010;37:2188-2193.

36. Rosen MA, Jones RM, Yano Y, Budinger TF. Carbon-11 choline: synthesis, purification, and brain uptake inhibition by 2-dimethylaminoethanol. $\mathrm{J} \mathrm{Nucl}$ Med. 1985;26:1424-1428.

37. Kwee S, Turner H, Lim J, Wakano C, Coel M. Dimethylaminoethanol reduces ${ }^{18} \mathrm{~F}$-fluoroethylcholine uptake in prostate cancer cells [abstract]. J Nucl Med. 2006;47(suppl 1):425P.

38. Hara T. ${ }^{18}$ F-fluorocholine: a new oncologic PET tracer. J Nucl Med. 2001; 42:1815-1817.

39. Kwee SA, DeGrado TR, Talbot JN, Gutman F, Coel MN. Cancer imaging with fluorine-18-labeled choline derivatives. Semin Nucl Med. 2007;37:420428.

40. Bansal A, Shuyan W, Hara T, Harris RA, Degrado TR. Biodisposition and metabolism of $\left[{ }^{18} \mathrm{~F}\right]$ fluorocholine in $9 \mathrm{~L}$ glioma cells and $9 \mathrm{~L}$ glioma-bearing Fisher rats. Eur J Nucl Med Mol Imaging. 2008;35:1192-1203.

41. Leyton J, Smith G, Zhao Y, et al. $\left[{ }^{18} \mathrm{~F}\right]$ fluoromethyl-[1,2- $\left.{ }^{2} \mathrm{H}_{4}\right]$-choline: a novel radiotracer for imaging choline metabolism in tumors by positron emission tomography. Cancer Res. 2009;69:7721-7728.

\section{Errata}

The article with a DOI of 10.2967/jnumed.111.091231 has been retracted at the request of the Editor in Chief.

In the article "Prognostic Value of ${ }^{18}$ F-FDG PET in Monosegmental Stenosis and Myelopathy of the Cervical Spinal Cord" by Floeth et al. (J Nucl Med. 2011;52:1385-1391), one author was inadvertently omitted from the byline. The corrected byline and affiliations appear below. The authors regret the error.

Frank W. Floeth ${ }^{1,2}$, Gabriele Stoffels ${ }^{3}$, Jörg Herdmannn ${ }^{1,2}$, Sven Eicker $^{1}$, Norbert Galldiks ${ }^{3,4}$, Sascha Rhee ${ }^{2}$, HansJakob Steiger ${ }^{1}$, and Karl-Josef Langen ${ }^{3}$

${ }^{1}$ Department of Neurosurgery, Heinrich-Heine-University, Düsseldorf, Germany; ${ }^{2}$ Department of Spine and Pain, St.Vinzenz-Hospital, Düsseldorf, Germany; ${ }^{3}$ Institute of Neuroscience and Medicine, Forschungszentrum Jülich, Jülich, Germany; and ${ }^{4}$ Department of Neurology, University Hospital Cologne, Cologne, Germany 